\title{
Herbal Medicine for Oligomenorrhea and Amenorrhea: A Systematic Review of Ancient and Conventional Medicine
}

\author{
Arezoo Moini Jazani $\mathbb{D}^{1},{ }^{1}$ Kobra Hamdi $\mathbb{D}^{2},{ }^{2}$ Mojgan Tansaz, ${ }^{3}$ Hossein Nazemiyeh, \\ Homayoun Sadeghi Bazargani ${ }^{\circ},{ }^{5}$ Seyed Mohammad Bagher Fazljou, ${ }^{1}$ \\ and Ramin Nasimi Doost Azgomi $\mathbb{1}^{1}$ \\ ${ }^{1}$ Department of Iranian Traditional Medicine, School of Traditional Medicine, Tabriz University of Medical Sciences, Tabriz, Iran \\ ${ }^{2}$ Women's Reproductive Health Research Center, Tabriz University of Medical Sciences, Tabriz, Iran \\ ${ }^{3}$ Department of Traditional Medicine, School of Traditional Medicine, Shahid Beheshti University of Medical Sciences, Tehran, Iran \\ ${ }^{4}$ Research Center for Pharmaceutical Nanotechnology, Faculty of Pharmacy, Tabriz University of Medical Sciences, Tabriz, Iran \\ ${ }^{5}$ Road Traffic Injury Research Center, Tabriz University of Medical Sciences, Tabriz, Iran
}

Correspondence should be addressed to Kobra Hamdi; hamdi_kobra@yahoo.com

Received 23 September 2017; Accepted 8 February 2018; Published 18 March 2018

Academic Editor: Gail B. Mahady

Copyright (C) 2018 Arezoo Moini Jazani et al. This is an open access article distributed under the Creative Commons Attribution License, which permits unrestricted use, distribution, and reproduction in any medium, provided the original work is properly cited.

\begin{abstract}
Introduction. Menstrual bleeding cessation is one of the most frequent gynecologic disorders among women in reproductive age. The treatment is based on hormone therapy. Due to the increasing request for alternative medicine remedies in the field of women's diseases, in present study, it was tried to overview medicinal plants used to treat oligomenorrhea and amenorrhea according to the pharmaceutical textbooks of traditional Persian medicine (TPM) and review the evidence in the conventional medicine. Methods. This systematic review was designed and performed in 2017 in order to gather information regarding herbal medications of oligomenorrhea and amenorrhea in TPM and conventional medicine. This study had several steps as searching Iranian traditional medicine literature and extracting the emmenagogue plants, classifying the plants, searching the electronic databases, and finding evidences. To search traditional Persian medicine references, Noor digital library was used, which includes several ancient traditional medical references. The classification of plants was done based on the repetition and potency of the plants in the ancient literatures. The required data was gathered using databases such as PubMed, Scopus, Google Scholar, Cochrane Library, Science Direct, and web of knowledge. Results. In present study of all 198 emmenagogue medicinal plants found in TPM, 87 cases were specified to be more effective in treating oligomenorrhea and amenorrhea. In second part of present study, where a search of conventional medicine was performed, 12 studies were found, which had 8 plants investigated: Vitex agnus-castus, Trigonella foenum-graecum, Foeniculum vulgare, Cinnamomum verum, Paeonia lactiflora, Sesamum indicum, Mentha longifolia, and Urtica dioica. Conclusion. Traditional Persian medicine has proposed many different medicinal plants for treatment of oligomenorrhea and amenorrhea. Although just few plants have been proven to be effective for treatment of menstrual irregularities, the results and the classification in present study can be used as an outline for future studies and treatment.
\end{abstract}

\section{Introduction}

Oligomenorrhea and amenorrhea are one of the most common gynecologic complaints among women in reproductive age. Prevalence of oligomenorrhea and secondary amenorrhea has been reported to be 10-15 percent and 3-4 percent, respectively $[1,2]$. Regardless of the diagnosis, oligomenorrhea and amenorrhea are changes in regular menstrual cycles which include long menstrual cycles and absence of menstruation, respectively [3]. Hormonal therapy based on estrogen and progesterone compounds is the mainstay of the treatment for these conditions [4].

Nowadays there has been an increasing trend in usage of complementary and alternative medicine (CAM) [5]. Traditional Persian medicine (TPM), as a holistic system of medicine and based on temperament, is one of the wealthiest 
branches of the CAM and has been used in Iran since thousands years ago [6]. Temperament is made of action and reaction of four pivotal elements (fire, air, water, and soil) and creates different characteristics in living things [7]. In TPM, temperament has been classified in different types: hot, cold, wet, and dry [8]. Any disturbances in normal temperament of organs (as said mal-temperaments) can cause diseases. Treatment is based on modifying the temperament [9]. Amenorrhea, oligomenorrhea, and hypomenorrhea are defined as "Ehtebas Tams" in TPM. From TPM viewpoint, anatomical and functional disorders (mal-temperaments) in the uterus and ovaries and other organs aside from the genital system are the main causes of oligomenorrhea and amenorrhea [10]. The treatment of oligomenorrhea and amenorrhea includes lifestyle modification (especially nutritional habits and diet, physical activities, and sleep), medication, and nonmedical methods like wet and dry cupping and surgery $[11,12]$. Herbal medications are one of the key tenets for treatment and can modify mal-temperaments of the organs $[11,12]$.

The aim of our study was to overview medicinal plants used to treat oligomenorrhea and amenorrhea according to the medical and pharmaceutical textbooks of TPM and review the evidence in the conventional medicine in order to recommend more efficient treatment guidelines for the research priorities in the future and also help to treat the patients by new pharmaceutical formulations.

\section{Methods}

This systematic review was designed and performed in 2017 in order to gather information regarding herbal medications of oligomenorrhea and amenorrhea in TPM and conventional medicine. This study had five steps: (1) searching Iranian traditional medicine literature and extracting the emmenagogue plants; (2) classification of the plants; (3) searching and extracting the scientific name of the plants; (4) searching the electronic databases and finding evidences; (5) ranking the data found in the studies. To search TPM references, Noor digital library was used, which includes several ancient traditional medical references (Table 1). This valuable database contains more than thousand Islamic and TPM books. The main keywords were "Moder Heiz or Tams," "Ehtebas Heiz or Tams," "Tams," "Heiz," and any words in Persian or Arabic that meant causing menstrual bleeding. In this part, the emmenagogue plants were identified and selected. The traditional name, temperament, and the exact phrases about its function in reproductive system and occurring menstruation were extracted.

The medicinal plants listed in the past step were classified in second step. The classification of plants was done based on the repetition and potency of the plants in the ancient literatures. A repetitious plant was defined as a plant which was repeated at least in 5 pharmaceutical textbooks of traditional Persian medicine (Table 1) [11, 13-16, 18, 19, 27]. In addition, the potent plants were isolated from the preliminary list. Potent, experienced, specific, unique plants were defined as medicinal herbs which were powerful or special or experienced in menstrual induction according to traditional Persian medicine scientists' concept. The used part and application method of the plants were also extracted.

In third step, the scientific name of frequent and potent plants was quested and extracted from some botanical reference books, databases, and articles such as "Popular Medicinal Plants of Iran" [20], "Matching the Old Medicinal Plant Names with Scientific Terminology" [21], "Dictionary of Iranian Plant Names" [22], "Dictionary of Medicinal Plants" [23], and "The Plant List" [40].

In fourth step, to investigate relevant information in conventional medicine required data was gathered by using databases such as PubMed, Scopus, Google Scholar, Cochrane Library, Science Direct, and web of knowledge. Time period between 2000 and 2017 was selected. Also, to increase scope of study, manual search in some of the valid journal databases was performed. The search terms were the scientific/common name of each plant in the whole text AND "oligomenorrhea" OR "amenorrhea" OR "polycystic ovary" OR "PCOs" OR "ovarian" OR "mense" OR "menstruation" OR "menstrual" OR "emmenagogue" in title/abstract. As far as polycystic ovary syndrome is known to be one of the main causes of oligomenorrhea and secondary amenorrhea, articles regarding use of herbal medicine in polycystic ovary syndrome were also included in the study to enrich the articles collection. In the fifth step, the ranking will be based on the data extracted from steps two to four.

One reviewer extracted the data from the included studies while a second author checked the results. Any disagreements were resolved by discussion of reviewers. Data for the primary objective of the review was collected from the full text of each publication and included the trial name, year of publication, type of study, sample size, results, and other details. Flowchart regarding classification of the medicinal plants is shown in Figure 1.

Statistical analysis was performed by SPSS software package version 16.0 for windows (SPSS Inc., Chicago, USA).

\section{Results}

In present study of all 198 herbs found in TPM [20-22, 24], 87 medicinal plants were found to be potent and frequent in treating oligomenorrhea and amenorrhea (Table 4); families Apiaceae (15.11\%) and Lamiaceae (12.79\%) were the most prevalent ones. Proportion of temperaments of these plants are shown in Figure 2. Based on the search of TPM, 70 medicinal plants were mentioned frequently to be effective in treatment of oligomenorrhea and amenorrhea and 50 medicinal plants were known as potent medicine for oligomenorrhea and amenorrhea treatment. Of all these plants, 33 were both frequently mentioned and potent (Tables 3 and 4$)$.

In second part of present study, where a search of conventional medicine was performed, 12 studies were found (Table 5) which had 8 plants investigated: Vitex agnus-castus, Trigonella foenum-graecum, Foeniculum vulgare, Cinnamomum verum, Paeonia lactiflora, Sesamum indicum, Mentha longifolia, and Urtica dioica. Details of included studies are 


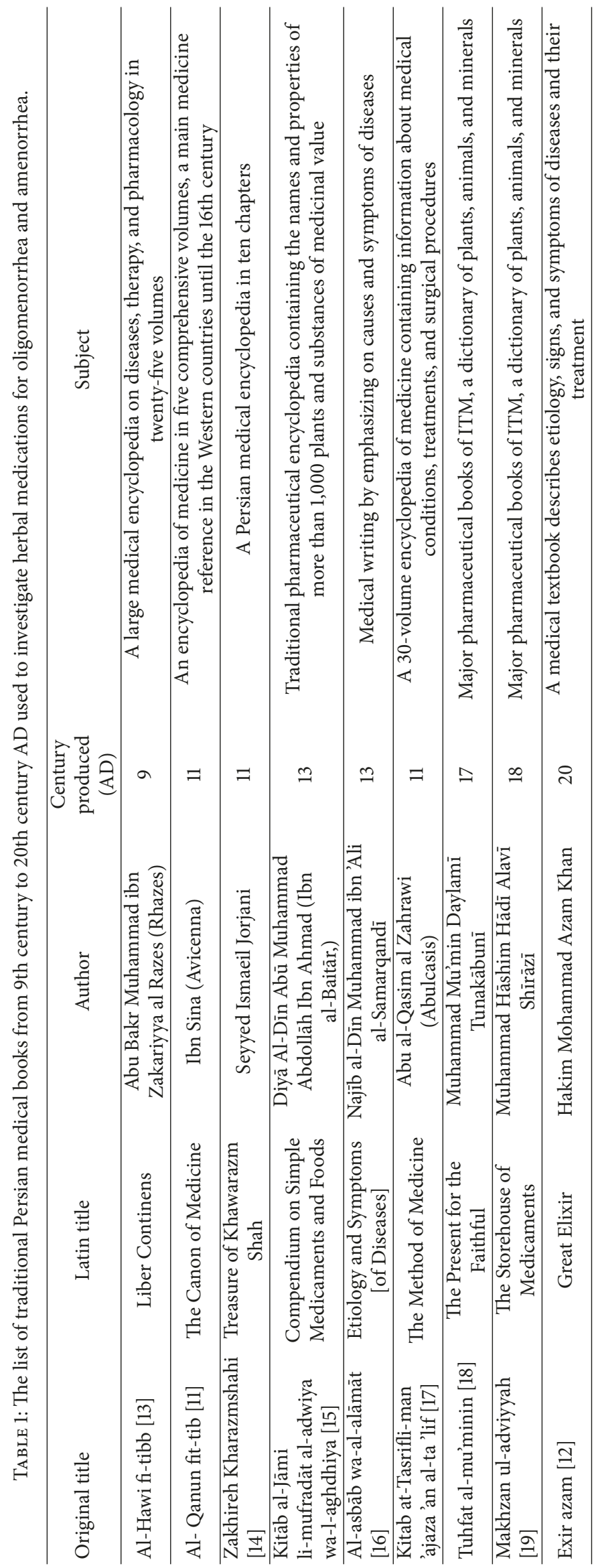




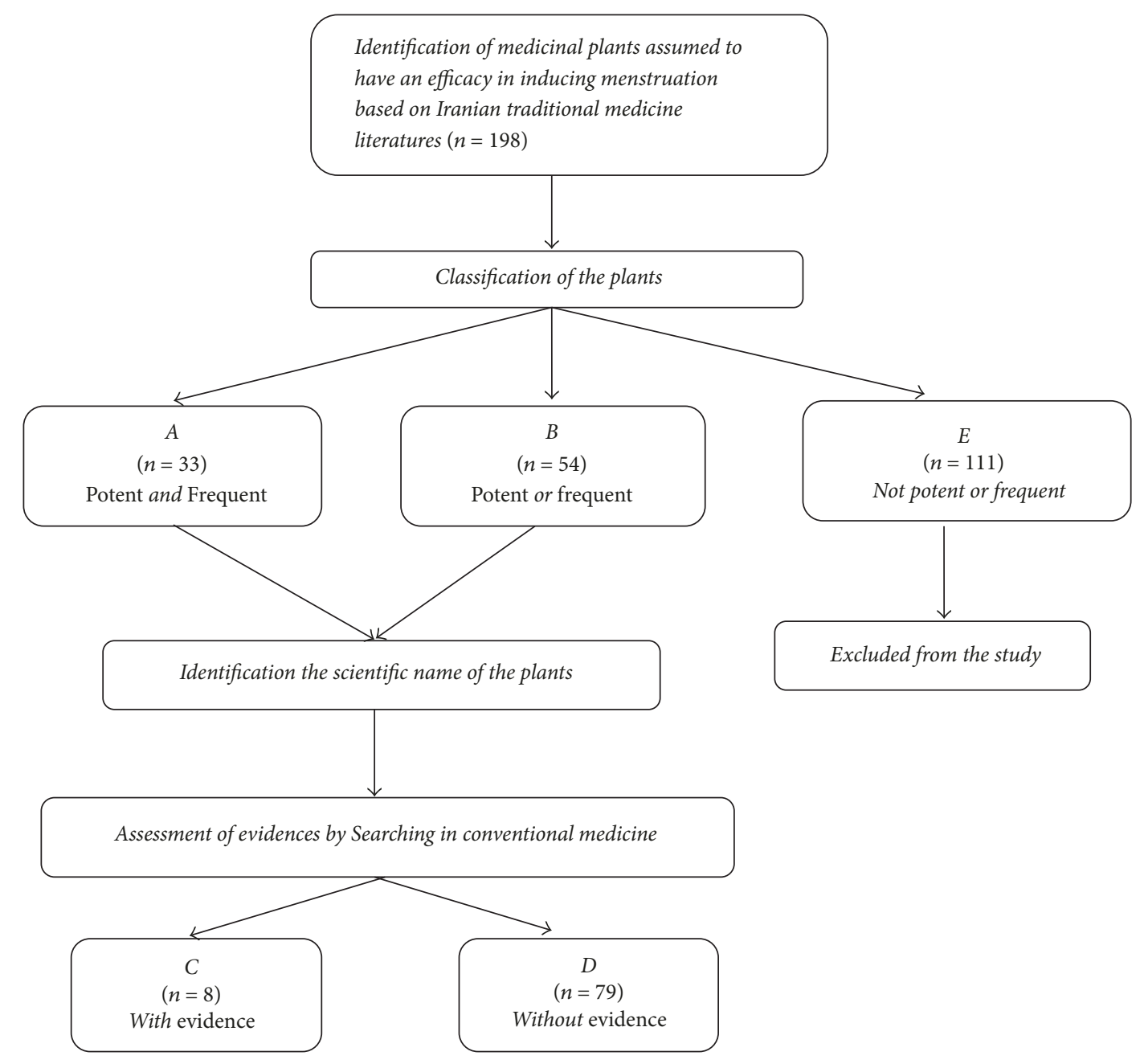

FIGURE 1: Flowchart regarding classification of medicinal plants used for treatment of oligomenorrhea and amenorrhea.

shown in Table 5. Nigella sativa, Thymus serpyllum, Matricaria chamomilla, Pimpinella anisum, Marrubium vulgare, Ziziphora clinopodioides, Origanum majorana, and Allium cepa are of the medicinal plants found to be effective in treatment of polycystic ovary syndrome; no therapeutic effect for oligomenorrhea and amenorrhea was mentioned [4148]. The flowchart of the systematic review is shown in Figure 3.

3.1. Vitex agnus-castus. Vitex agnus-castus or chasetree belongs to family Lamiaceae, which has been used as a common medicine for treatment of menstrual irregularities and infertility since 2000 years ago $[38,39]$. The effects of low dose estrogen and Vitex agnus-castus on the normalization of the menstrual cycle and the means of serum prolactin and free testosterone levels in the women with polycystic ovary syndrome were similar [39].

3.2. Trigonella foenum-graecum. Trigonella foenum-graecum is an annual plant belonging to family Fabaceae found in Mediterranean region and Iran. It has been traditionally used for gastrointestinal, pulmonary, and gynecologic diseases [19]. Based on the studies, this medicinal plant has been found effective in regulating menstrual cycles, improving fertility, and reversing features of polycystic ovary syndrome by decreasing $\mathrm{LH}$ to $\mathrm{FSH}$ ratio and reversing ultrasonographic features of it $[35,36]$.

3.3. Cinnamomum verum. Cinnamon is an evergreen plant from family Lauraceae with aromatic characteristics basically used as a condiment. In TPM, this plant is known as a potent medicine to increase libido and regulate menstruation and is effective in treating brain and pulmonary diseases [19]. Anti-inflammatory, antioxidative, antidiabetic, and lipid lowering features of cinnamon has been already proven [49]. Cinnamon is known to increase serum progesterone level in luteal phase, so facilitating menstrual cycle regulation [28].

3.4. Paeonia lactiflora Pall. Paeonia lactiflora Pall is a medicinal plant used in Japan, Korea, China, and Iran since 1200 years. It has been used to cure stomachache, headache, 


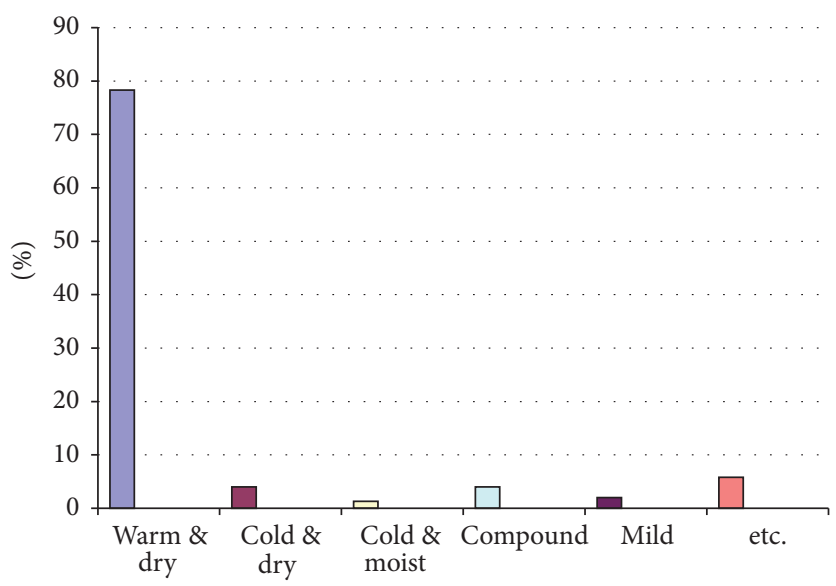

FIGURE 2: Proportion of temperament of medicinal plants found in present study.

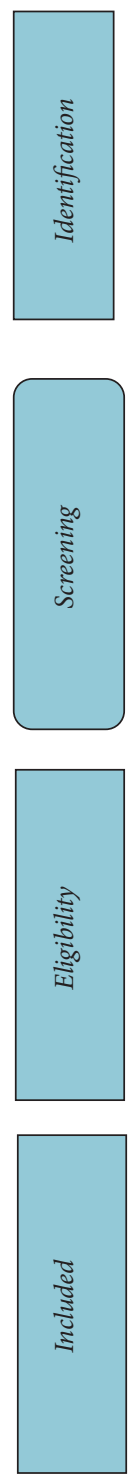

Records identified through database searching $(n=158)$

Manual search $(n=11)$

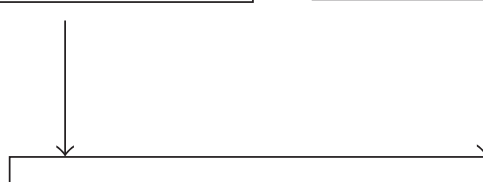

Records after duplicates removed $(n=169)$

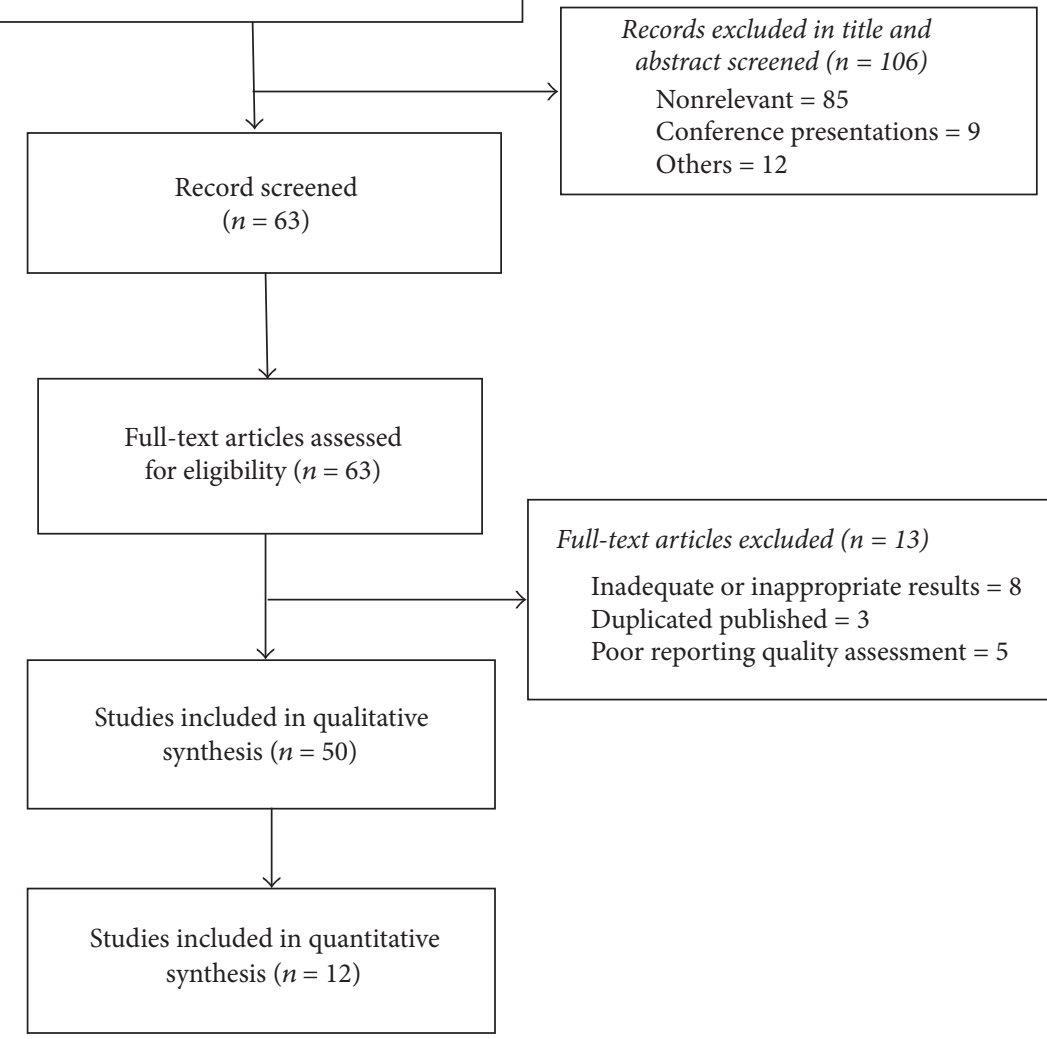

FIGURE 3: Flowchart of the systematic review of conventional medicine references to assemble studies regarding herbal medicines used for treatment of oligomenorrhea and amenorrhea. 
hepatitis, dysmenorrhea, and menstrual cycle irregularities [19]. It has been already reported that a mixture of Paeonia lactiflora and Glycyrrhiza glabra extracts was effective in normalizing menstrual cycles and hormonal balance among women with polycystic ovary syndrome [32].

3.5. Foeniculum vulgare. Foeniculum vulgare or Fennel is a flowering plant from family Apiaceae which has been used as a medicinal plant in TPM due to its known antioxidative, anti-inflammatory, estrogenic, diuretic, emmenagogue, antithrombotic, and antihypertensive features [26]. This plant has been found to be effective in inducing menstruation after medroxyprogesterone acetate use in comparison to control group [29].

3.6. Mentha longifolia. Mentha longifolia is one of many members of family Lamiaceae which is used in pharmaceuti$\mathrm{cal}$ and industrial fields. This medicinal plant has been used to relieve gastrointestinal and gynecologic complaints for many years $[19,50]$. It has been shown that using Mentha longifolia extracts induces menstruation and regulates menstrual cycles [30]. Also it has been indicated that this extract decreases FSH and induces menstruation among patients with primary ovarian failure [31].

3.7. Sesamum indicum. Sesamum indicum is a flowering plant in the genus Sesamum and family Pedaliaceae. In TPM, this medicinal plant has been used to increase libido, induce menstrual bleeding, and treat renal and pulmonary diseases [34]. Also, sesame has been found to have antihypertensive, antioxidant, and cholesterol lowering characteristics $[33,34]$. Sesame is known to induce menstruation without prominent side effects among women with severe oligomenorrhea [33, 34].

3.8. Urtica dioica. Urtica dioica is a herbaceous perennial flowering plant in the family Urticaceae, which has been used as a diuretic and to treat rheumatic diseases and arthritis [37]. Ancient Iranian physicians used Urtica dioica to increase libido, induce menstruation, and treat renal and pulmonary diseases [19]; also this plant has been found to have antioxidant, anti-inflammatory, antidiabetic, and antiandrogenic features; although based on a study Urtica dioica extract improved the clinical and paraclinical symptoms of hyperandrogenism in women, improvement of menstrual irregularities was lower in the intervention group compared to the control group [37].

\section{Discussion}

It deems that diseases of female reproductive system are one of the greatest challenges for modern medicine. Menstrual irregularities as one of the most frequent gynecologic complaints can affect the several aspects of women's health including their physical, mental, and social health $[51,52]$. Oligomenorrhea and its different etiologies, especially PCOs, can lead to various complications such as infertility, pregnancy complications, cardiovascular disease, metabolic diseases like diabetes, hypertension, and fatty liver, and psychological disorders such as anxiety and depression and reduce quality of life in women [5254].

Nowadays, due to some complications of hormonal therapy, many women have considered using alternative and complementary medicine $[55,56]$. TPM is known as one of the main branches of alternative and complementary medicine, which tries to treat illnesses with change in lifestyle and using medicinal plants [57].

In present study, emmenagogue plants used to treat oligomenorrhea and amenorrhea were systemically searched. Based on current study, 33 plants were proven to be more effective (due to their potency and frequency in ancient literatures) in treatment of oligomenorrhea and amenorrhea in TPM (group A in Figure 1 and Table 3) as Prangos ferulacea L., Ferula persica Willd., Mentha longifolia, Artemisia absinthium, Thymus vulgaris, Phaseolus vulgaris, Ziziphora clinopodioides Lam., and so on according to Table 3. The most prevalent temperaments of the plants were warm and dry. Eight plants were found to be effective in conventional medicine references (group $\mathrm{C}$ in Figure 1 and Table 3): Cinnamomum verum, Foeniculum vulgare, Mentha longifolia, Paeonia lactiflora, Sesamum indicum L., Trigonella foenumgraecum, Urtica dioica, and Vitex agnus-castus. Of all these plants, 5 plants belonged to both groups (groups A and C): Foeniculum vulgare, Mentha longifolia, Paeonia lactiflora, Sesamum indicum L., and Vitex agnus-castus. The plants of group C did not have any serious side effects in the dosage and duration of use according to reviewed articles in present study. Phytochemical studies have shown that flavonoids (quercetin, apigenin, and vitexin), phenols (anethole and thymol), phytosterols (stigmasterol and sitosterol), lignans, and terpenoids are of the main components in these medicinal plants which are responsible for their medicinal activities [58]. Although the exact mechanisms of these plants on oligomenorrhea are not fully understood, the antioxidant and anti-inflammatory properties of these herbs are likely to be one of the main mechanisms of their function. The anti-inflammatory and antioxidative features of the plants have been proposed to play the key role in regulating sex hormones, increasing insulin sensitivity, and modifying lipid profile $[28,50,59,60]$. It has been reported that some of these plants contain phytoestrogenic components which lowers $\mathrm{LH}$ via a negative feedback process and decreases testosterone [61, 62]. Milewicz et al. showed that consumption of Vitex agnus-castus extract over a period of 3 months can reduce the prolactin release in latent hyperprolactinemia without significant side effect [63]. It has been proposed that some phytoestrogenic components in these plants with similar actions to natural sex hormones enhance follicle maturation, reduce coagulation factors, relax uterine muscles, and facilitate uterine recovery $[29,34,64$, 65].

Due to the paucity of studies on medicinal plants in the treatment of oligomenorrhea, the ranking of the plants in this study can be used to conduct further studies with a higher priority and also to treat the patients. According to the rankings (Table 2), the first group of the plants 
TABLE 2: Ranking the medicinal plants groups from the most efficient to the least efficient.

\begin{tabular}{lcc}
\hline Number & Group & Description \\
\hline$(1)$ & A + C & Potent and frequent with evidence \\
\hline$(2)$ & A + D & Potent and frequent without evidence \\
\hline$(3)$ & B + C & Potent or frequent with evidence \\
\hline$(5)$ & B + D & Potent or frequent without evidence \\
\hline
\end{tabular}

TABLE 3: Summary of plants found in traditional Persian medicine and conventional medicine references.

\begin{tabular}{|c|c|c|c|c|c|c|}
\hline Data & $\begin{array}{l}\text { Total } \\
\text { plants }\end{array}$ & $\begin{array}{l}\text { Potent } \\
\text { plants }\end{array}$ & $\begin{array}{l}\text { Frequent } \\
\text { plants }\end{array}$ & $\begin{array}{l}{ }^{*} \text { Potent and frequent } \\
\text { plants (group A in } \\
\text { flowchart of study) }\end{array}$ & $\begin{array}{l}{ }^{* *} \text { Plants with } \\
\text { evidences (group C in } \\
\text { flowchart of study) }\end{array}$ & $\begin{array}{l}{ }^{* * *} \text { Potent and } \\
\text { frequent plants with } \\
\text { evidences (group } 1 \text { in } \\
\text { ranking table) }\end{array}$ \\
\hline
\end{tabular}

${ }^{*}$ Allium ampeloprasum, Apium graveolens, Aristolochia fontanesii Boiss. \& Reut., Artemisia absinthium, Asarum europaeum, Brassica oleracea L., Cinnamomum cassia, Citrullus colocynthis, Commiphora mukul, Cyclamen purpurascens Mill., Daucus carota L., Foeniculum vulgare Mill., Ferula gummosa, Ferula persica Willd., Helleborus niger, Hypericum perforatum L., Levisticum officinale, Lilium candidum, Mentha longifolia, Nigella sativa L., Paeonia lactiflora Pall, Petroselinum crispum, Phaseolus vulgaris, Prangos ferulacea L., Rubia tinctorum, Sesamum indicum L., Tanacetum parthenium, Teucrium chamaedrys, Teucrium polium L., Thymus vulgaris, Urtica dioica, Vitex agnus-castus L., and Ziziphora clinopodioides Lam.; ${ }^{* *}$ Cinnamomum verum, Foeniculum vulgare, Mentha longifolia, Paeonia lactiflora, Sesamum indicum L., Trigonella foenum-graecum, Urtica dioica, and Vitex agnus-castus; ${ }^{* * *}$ Foeniculum vulgare, Mentha longifolia, Paeonia lactiflora, Sesamum indicum L., and Vitex agnus-castus.

which was potent and frequent and have herbal studies evidences can be used as an outline for future studies and treatment of patients. Design of in vitro, animal, and even clinical studies with more proper quality and larger sample size is recommended to reveal exact mechanisms of these plants and manufacture new pharmaceutical products with minimal side effects. Group 2 plants, which did not have enough evidence, are at the second rank which has the priority to be studied in clinical and preclinical settings in order to evaluate the efficacy, mechanisms of activities, safety, and any probable side effects. Groups 3 and 4 because of lack of evidence are at the next research priorities.

Polycystic ovary syndrome is a set of symptoms in women which includes irregular or no menstrual periods, excess body and facial hair, acne, and infertility [66]. In present study, Nigella sativa, Thymus vulgaris, Matricaria chamomilla, Pimpinella anisum, Marrubium vulgare, Ziziphora clinopodioides, Origanum majorana, and Allium cepa were found to be effective in treatment of polycystic ovary syndrome, but there were not any reports about the treatment of oligomenorrhea and amenorrhea. Due to the effects of the mentioned herbs in the treatment of clinical and paraclinical symptoms of PCOs, these plants also may be proposed as a potent treatment for oligomenorrhea and amenorrhea.

One of the main limitations of present study was the lack of the resources from the other alternative and complementary medicine references, such as those used in China; inclusion of information from those references would have enriched the present study in a way that a more concise conclusion could have been made.

\section{Conclusion}

In present study, it was tried to assemble the available evidence about effect of medicinal plants on treating oligomenorrhea and amenorrhea in Persian and conventional medicine references. At last 5 plants were found to be strongly suggested in TPM and also proven to be effective in conventional medicine references: Foeniculum vulgare, Mentha longifolia, Paeonia lactiflora, Sesamum indicum L., and Vitex agnus-castus. This result can be utilized in clinical fields, by selecting more efficient, with less side effects, medicinal herbs. Although a lot of emphasis has been made about plants in alternative and complementary medicine, unfortunately there have not been enough studies in conventional medicine. Results of present study can be used as an outline for future studies about the plants found to be effective in conventional and complementary medicine.

\section{Disclosure}

This research was presented as a Ph.D. thesis (Arezoo Moini Jazani, Thesis no. 5 ) at School of Traditional Medicine, Tabriz University of Medical Sciences.

\section{Conflicts of Interest}

The authors declare that they have no conflicts of interest. 


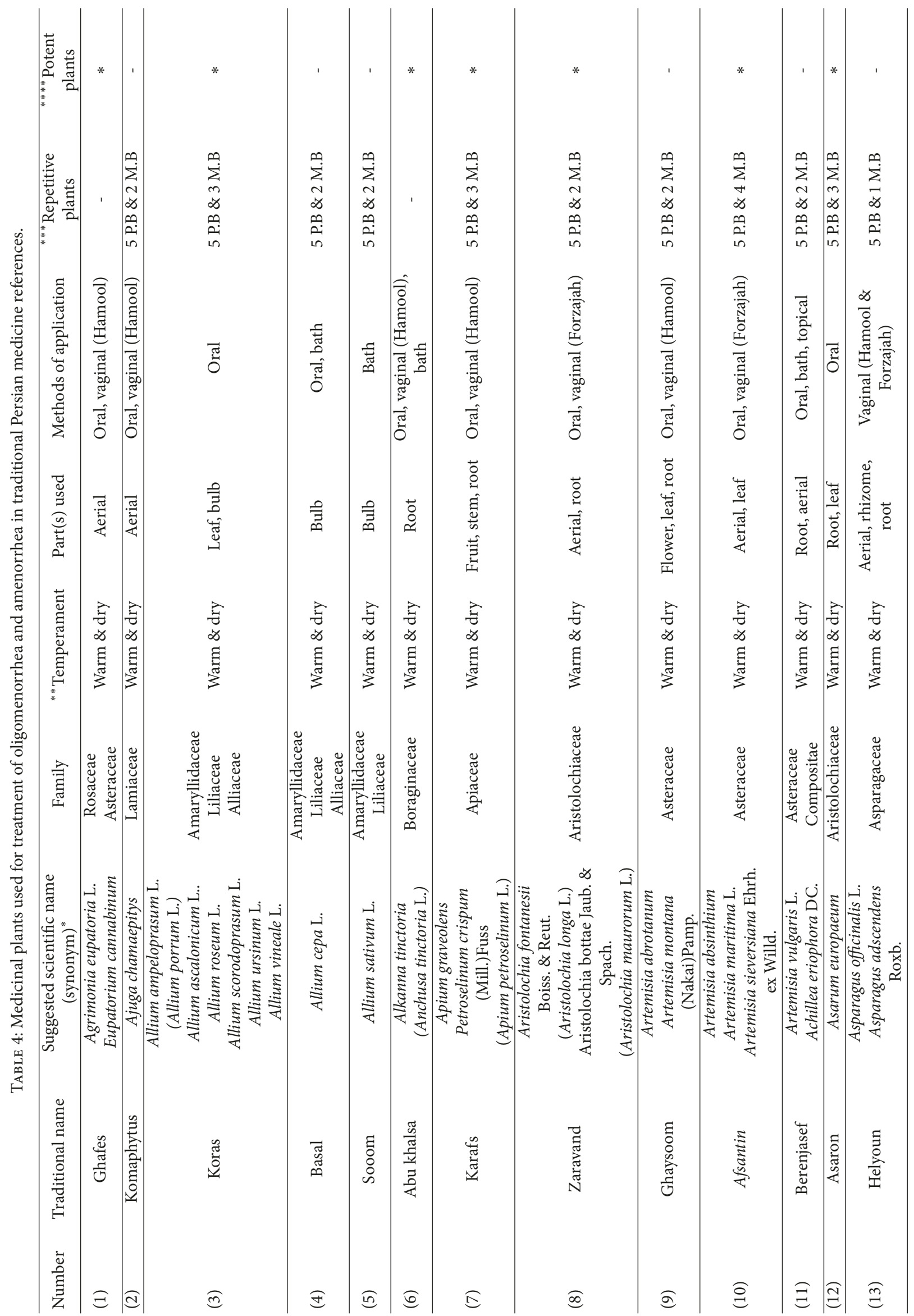




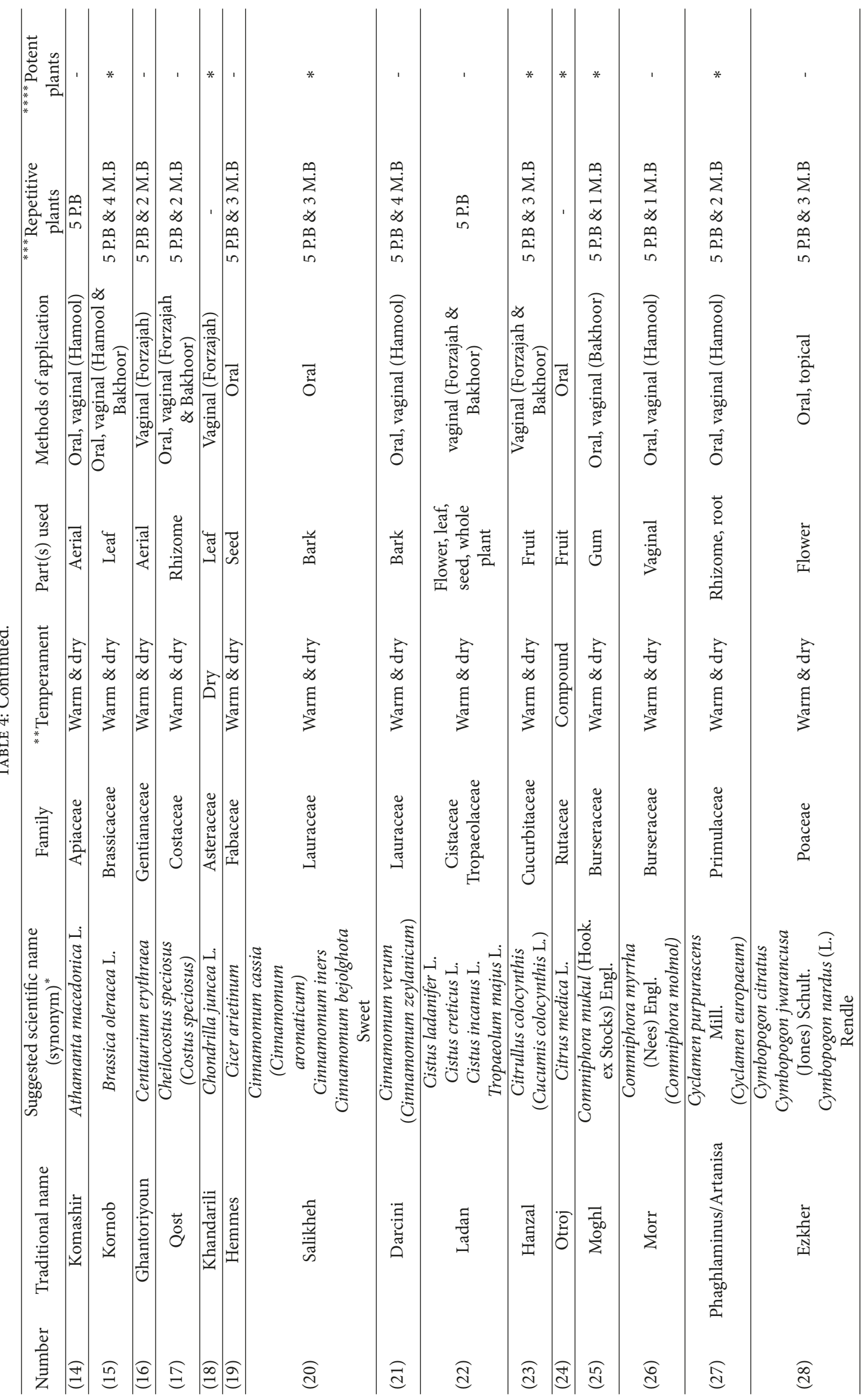




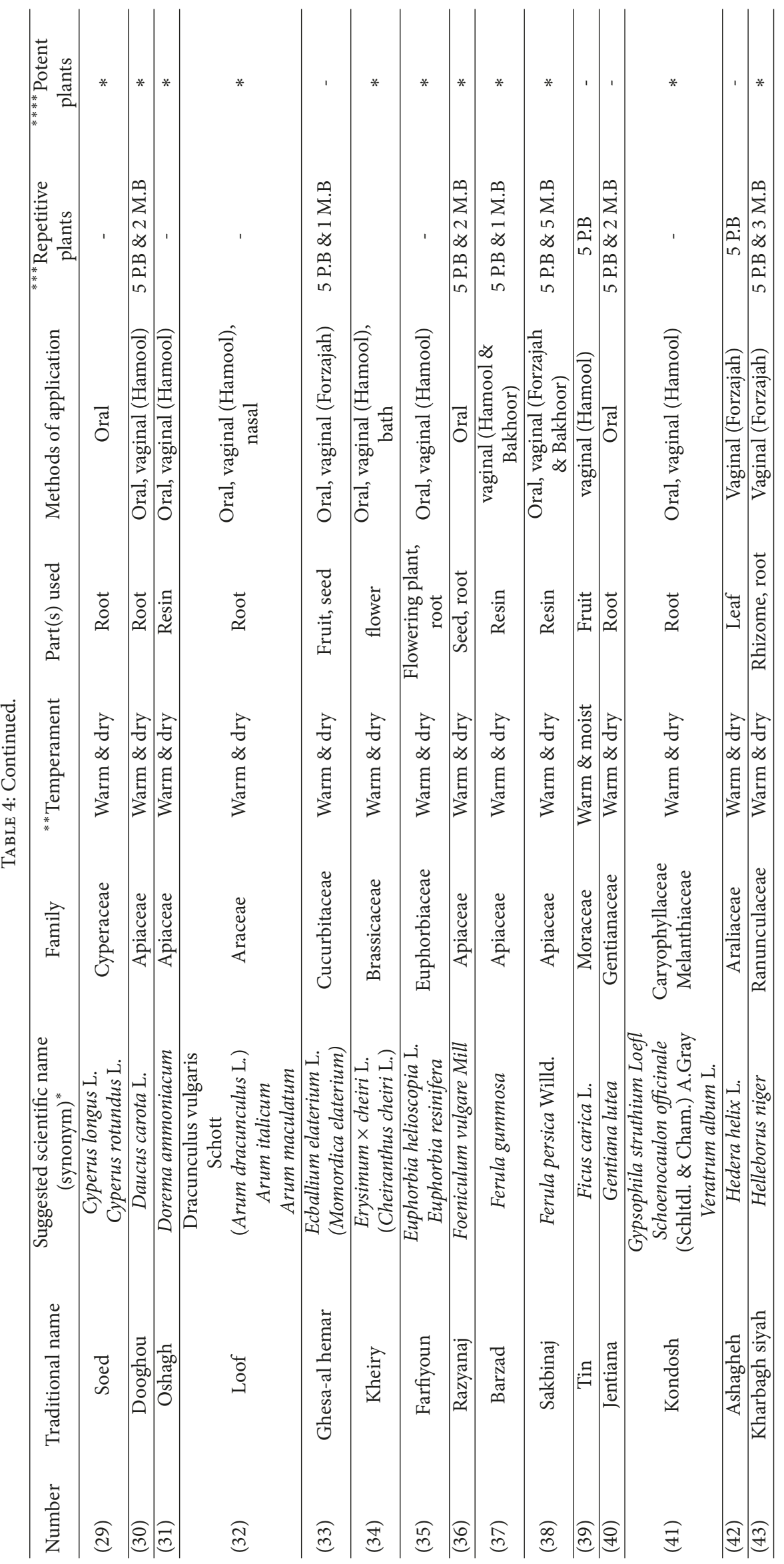




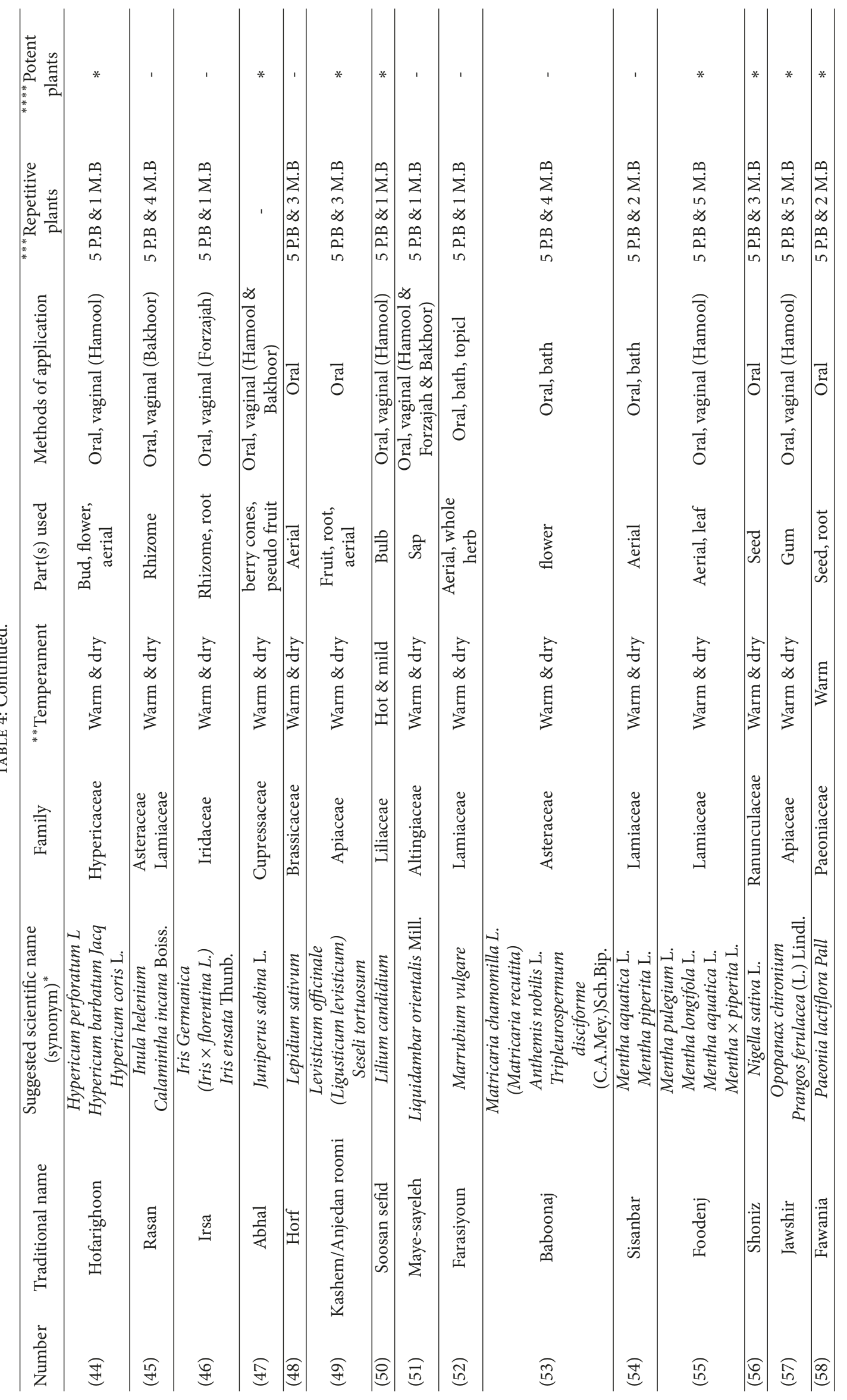




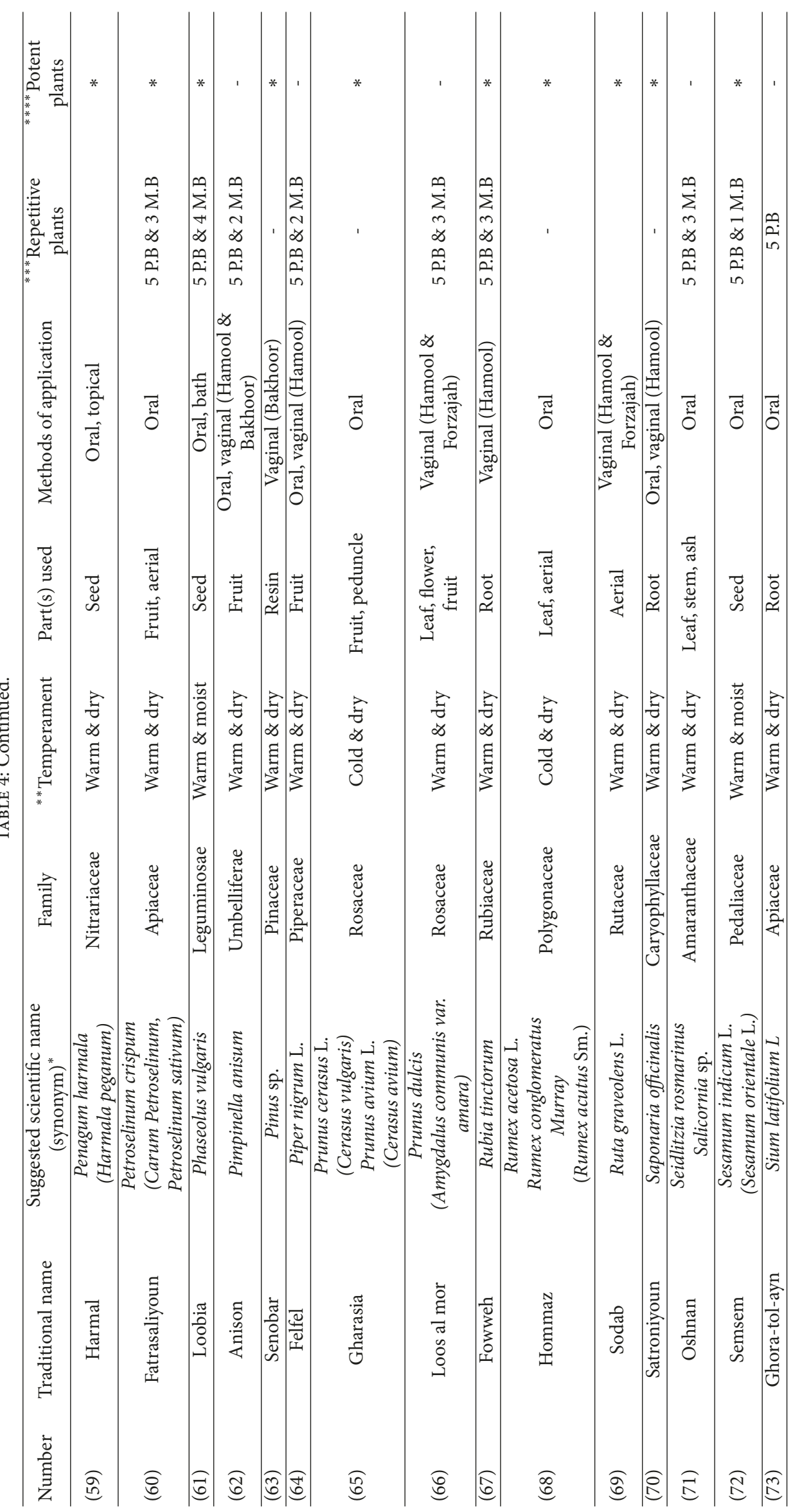




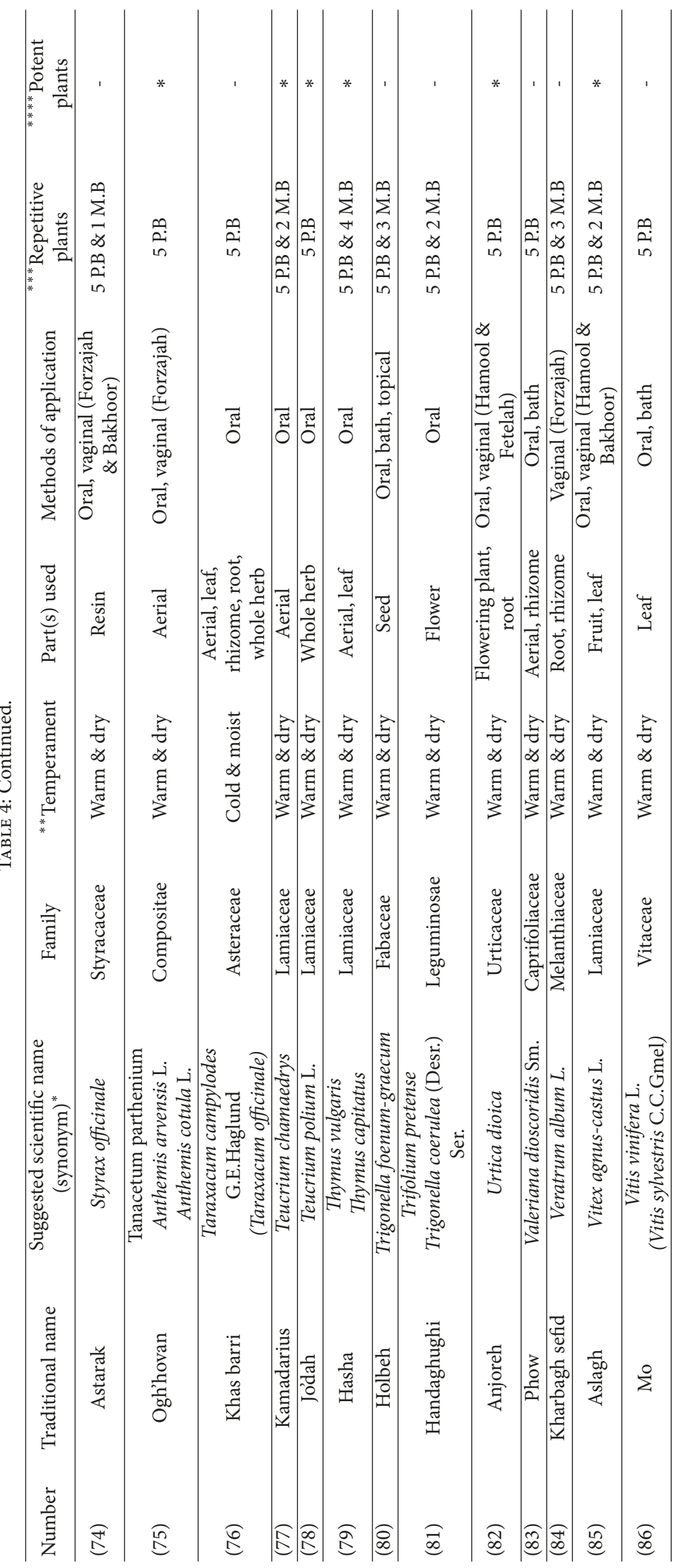




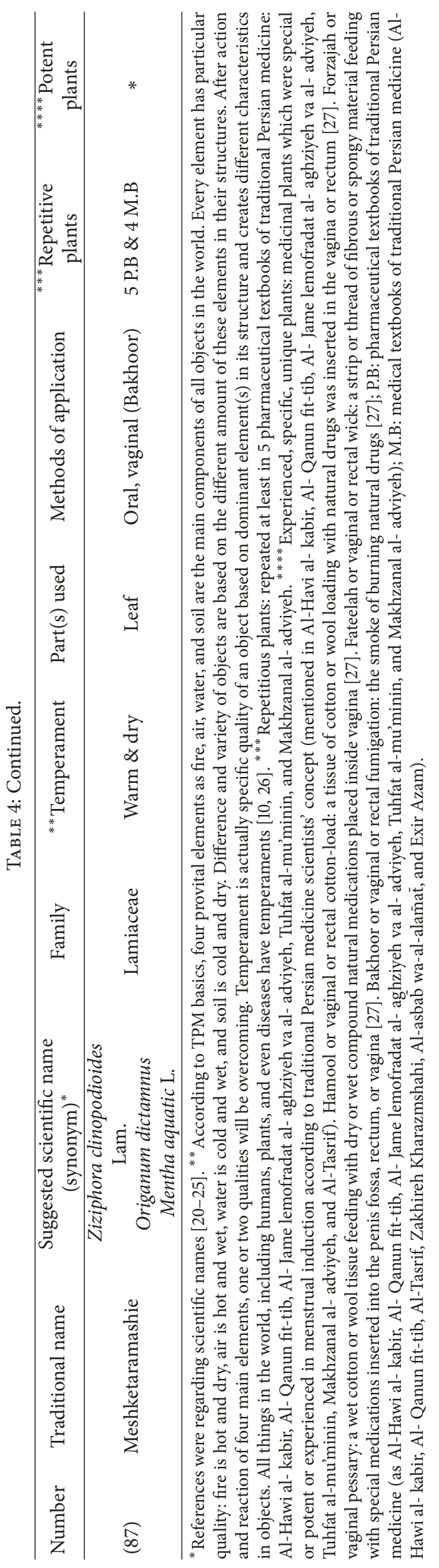




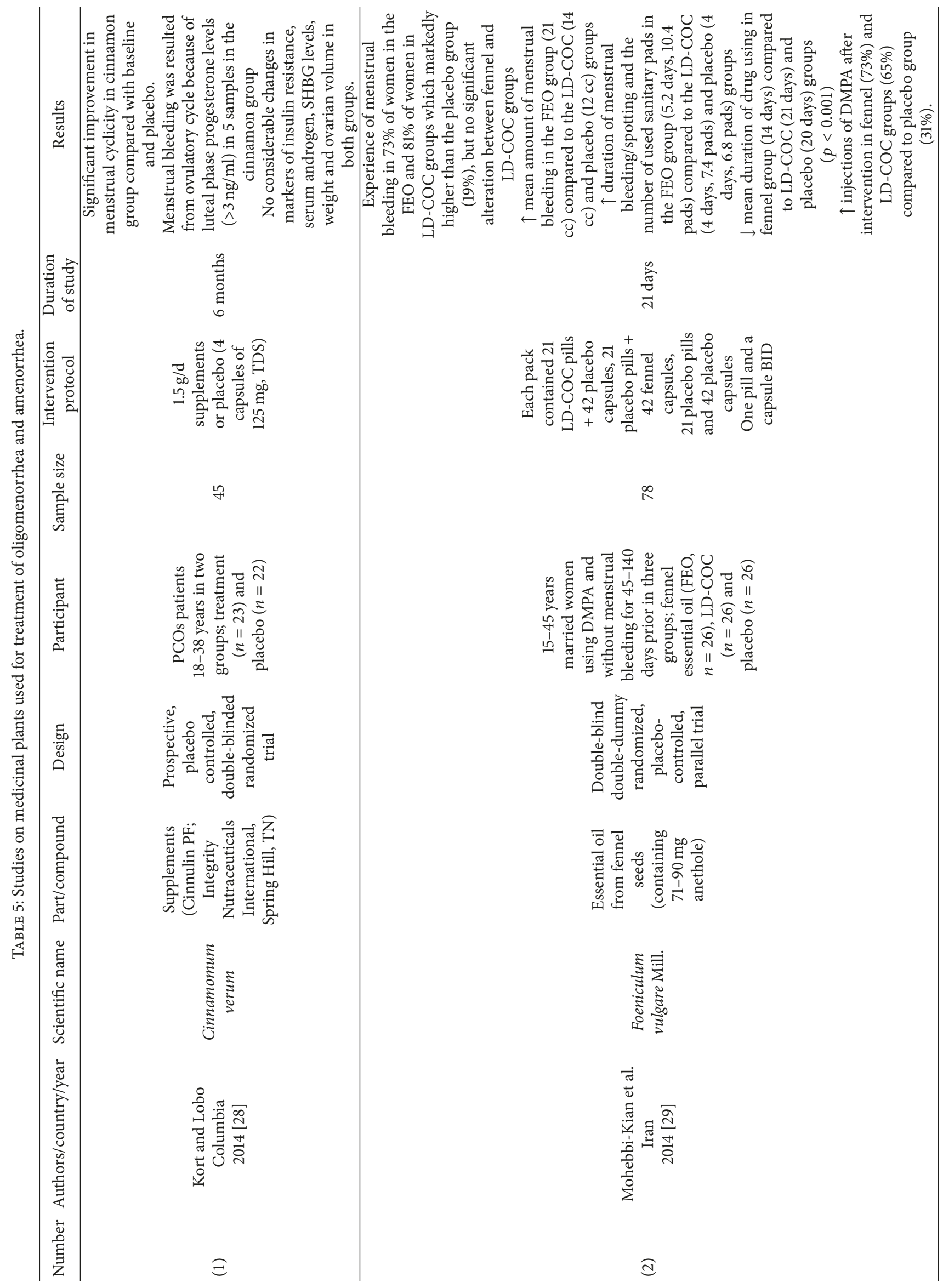




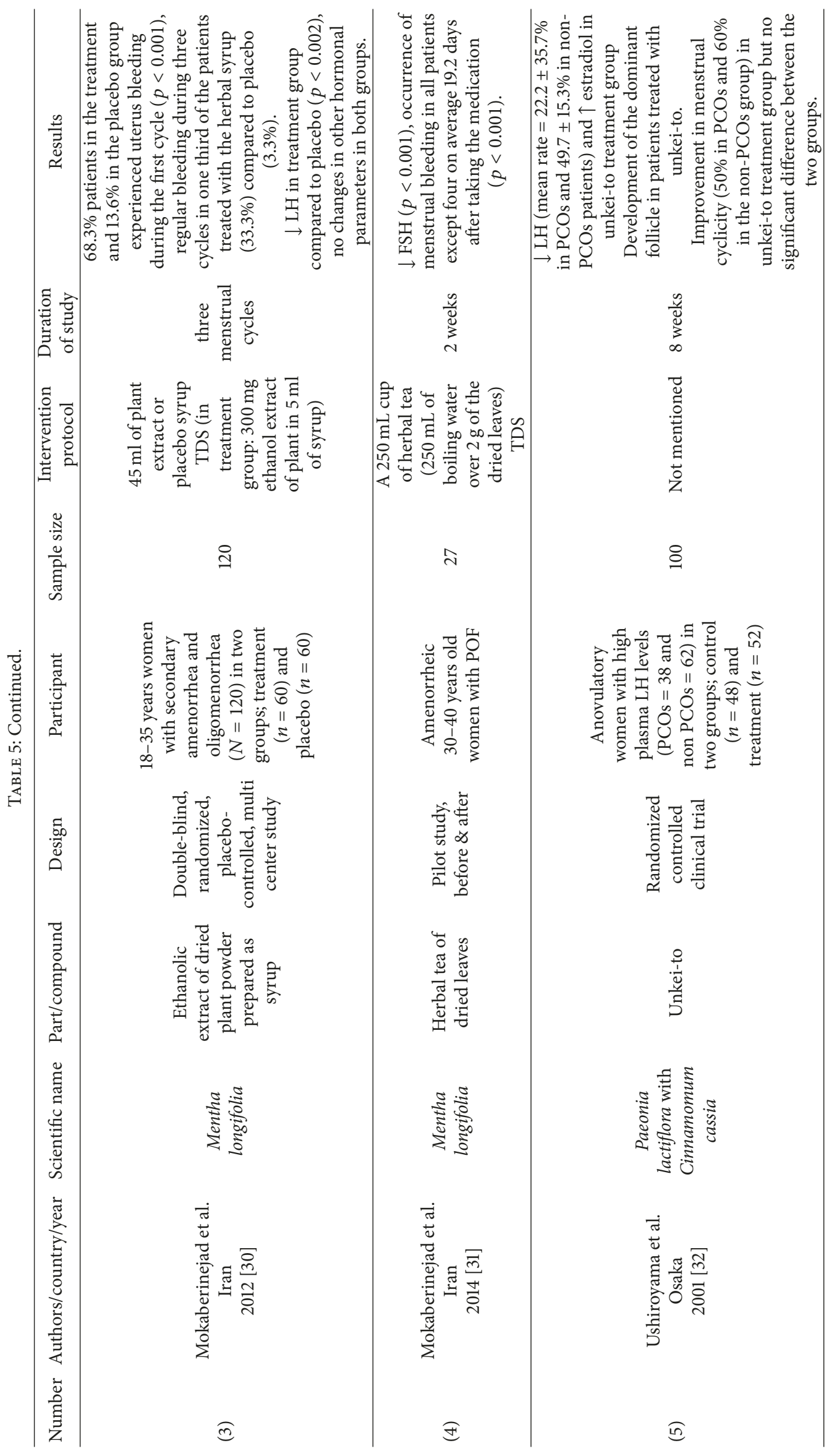




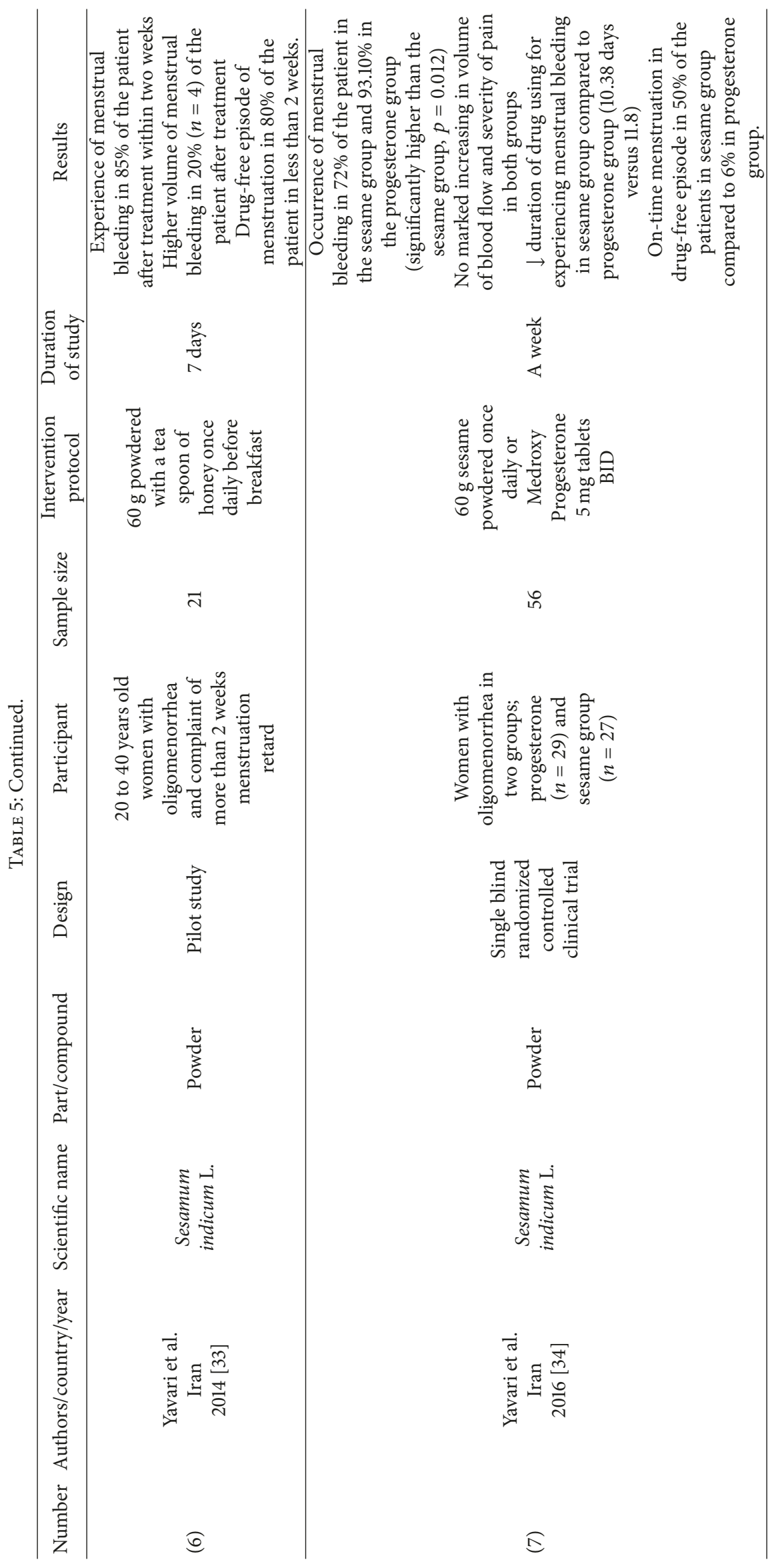




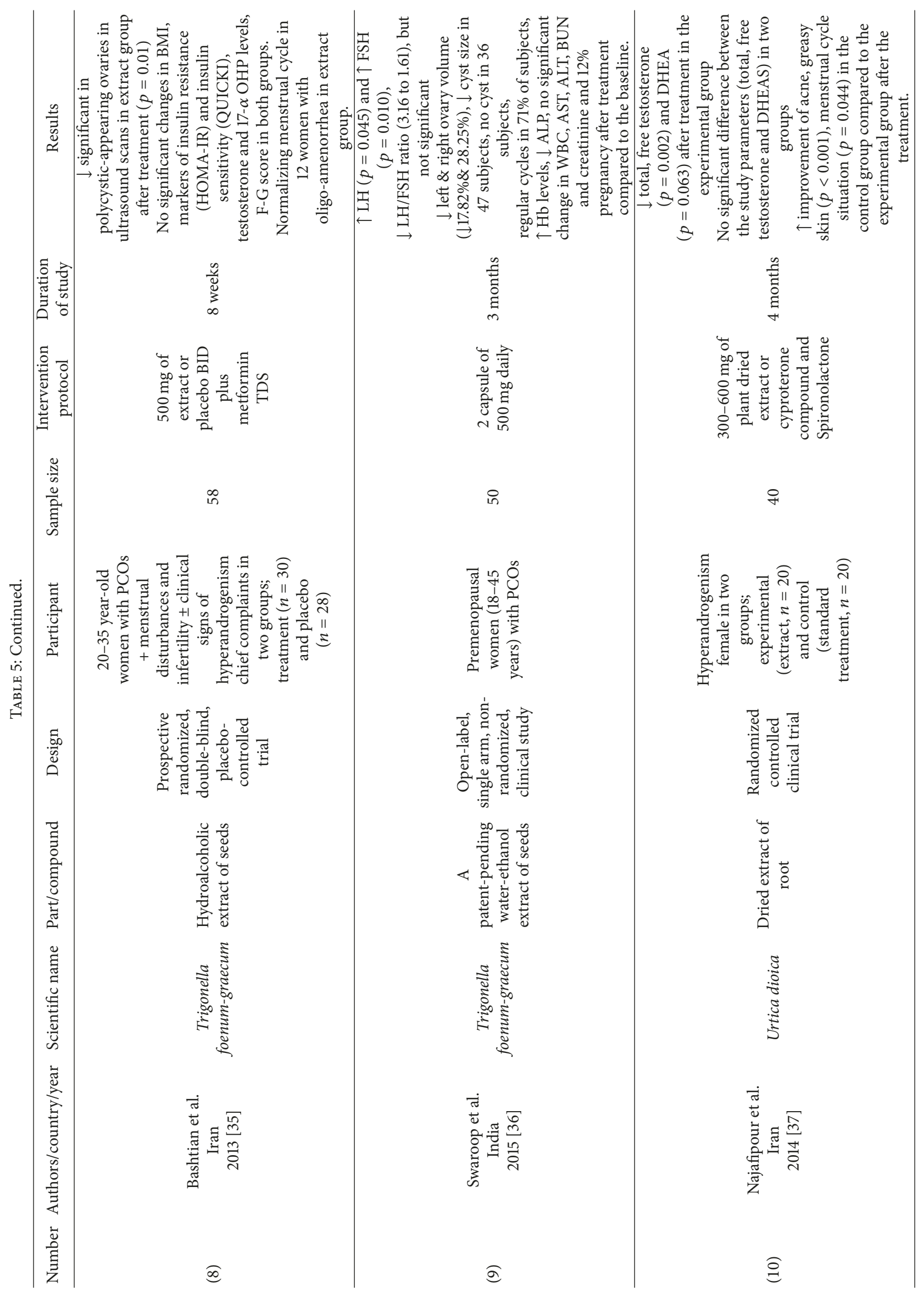




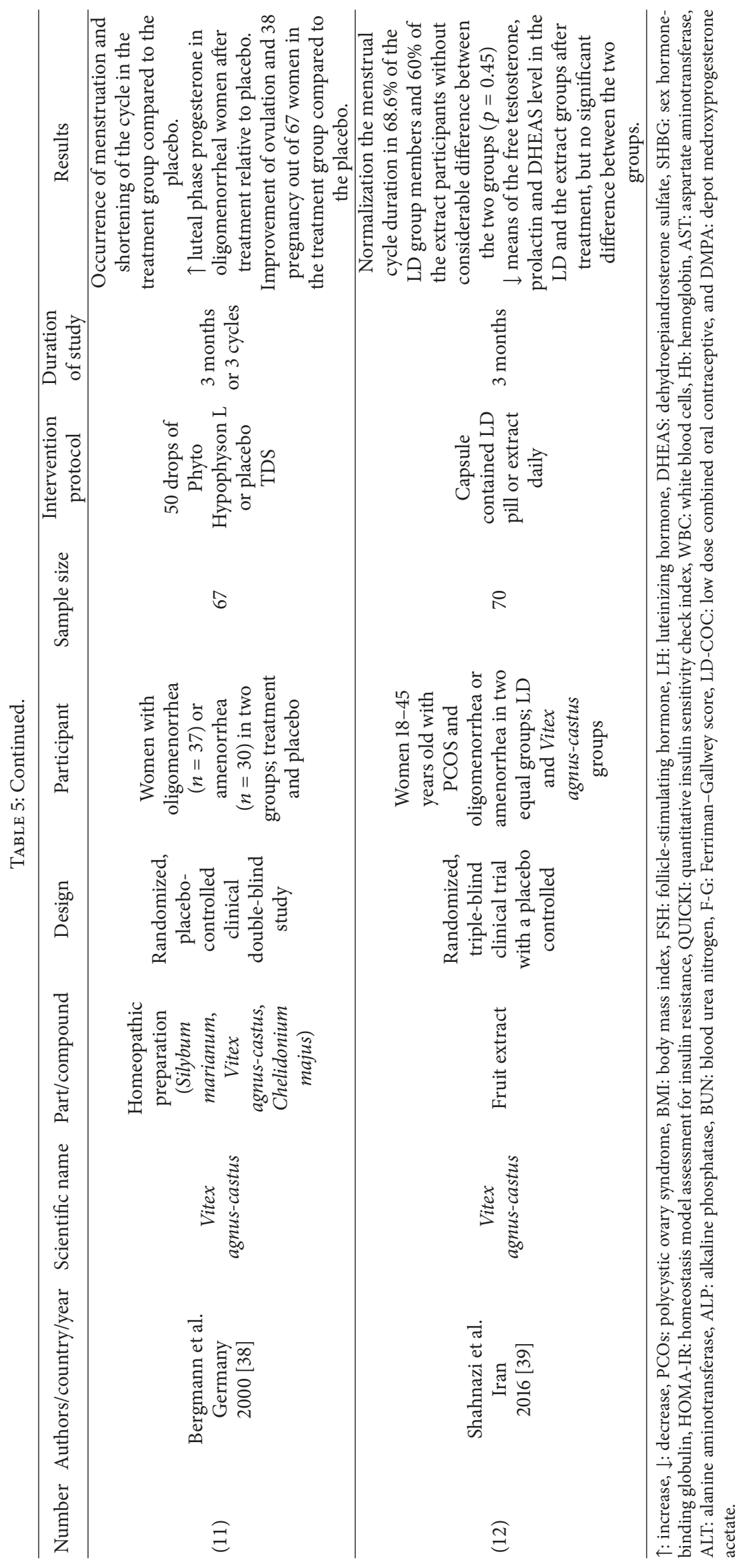




\section{Acknowledgments}

The authors are grateful to Tabriz University of Medical Sciences for support.

\section{References}

[1] R. S. Gibbs, B. Y. Karlyn, A. F. Haney, and I. Nygaard, Danforth's obstetrics and gynecology: Wolters Kluwer Health Adis (ESP), Wolters Kluwer Health Adis (ESP), 2012.

[2] E. Novak, Berek Novak's Gynecology, Lippincott Williams \& Wilkins, 2007.

[3] S. J. Emans, M. R. Laufer, and E. Laufer, Goldstein's Pediatric and Adolescent Gynecology, Lippincott Williams \& Wilkins, 2012.

[4] T. J. De Villiers, M. L. S. Gass, C. J. Haines et al., "Global consensus statement on menopausal hormone therapy," Climacteric, vol. 16, no. 2, pp. 203-204, 2013.

[5] WHO, WHO Traditional Medicine Strategy 2002-2005, 2002.

[6] A. Hamedi, M. M. Zarshenas, M. Sohrabpour, and A. Zargaran, "Herbal medicinal oils in traditional Persian medicine," Pharmaceutical Biology, vol. 51, no. 9, pp. 1208-1218, 2013.

[7] S. Shahabi, Z. M. Hassan, M. Mahdavi et al., "Hot and cold natures and some parameters of neuroendocrine and immune systems in traditional Iranian medicine: A preliminary study," The Journal of Alternative and Complementary Medicine, vol. 14, no. 2, pp. 147-156, 2008.

[8] H. Rezaeizadeh, M. Alizadeh, M. Naseri, and M. R. S. Ardakani, "The Traditional Iranian Medicine point Of view on health and disease," Iranian Journal of Public Health, vol. 38, no. 1, pp. 169172, 2009.

[9] L. Lu and C.-H. Hu, "Personality, leisure experiences and happiness," Journal of Happiness Studies, vol. 6, no. 3, pp. 325342, 2005.

[10] R. Rahimi and M. R. S. Ardekani, "Medicinal properties of Foeniculum vulgare Mill. in traditional Iranian medicine and modern phytotherapy," Chinese Journal of Integrative Medicine, vol. 19, no. 1, pp. 73-79, 2013.

[11] I. S. Avicenna, Kitāb al-Qānūn fì al-Tỉbb (Canon of medicine), Senior Press Superintendent, Jamia Hamdard Printing Press, New Delhi, India, 1998.

[12] M. A. K. Eksir-e-Azam, The Great Elixir, Tehran university of MedicalScience: Institute for Islamic and Complementary Medicine, Tehran, Iran, 3rd edition, 2007.

[13] M. Azeez Pasha, "Al-Hawi (liber continens) of Ar-Razi, Abu Bakr Muhammed Bin Zakariya; synopsis of the fourteenth volume. Part II.," Bulletin of the Indian Institute of History of Medicine (Hyderabad), vol. 7, no. 3-4, pp. 131-137, 1977.

[14] E. Jorjani, Zakhireye Khwaram Shahi (Treasure of Khwarazm Shah), S. Sirjani, Ed., Entesharat-e Bonyade Farhang-e, Tehran, Iran, 1976.

[15] I. al-Baytar, Kitāb al-Jāmi'li-Mufradāt al-'Adwiya wa-l'Aghdhiya, vol. 1, Maktabat al-Muthannā, 1874.

[16] A. Z. Iskandar, "A study of Al-Samarqandì's medical writings with special emphasis on his book Al-Asbāb wa Al-alāmāt (Causes and Symptoms), and Al-Kirmānī's Sharh Al-Asbāb wa Al-'alāmāt (Commentary on Causes and Symptoms)," Le Muséon, no. 3-4, pp. 451-479, 1972.

[17] A. Abu al-Qasim al Zahrawi, Kitab at-Tasrifli-man 'ajaza 'an al-ta 'lif, Tehran University of Medical Sciences, Tehran, Iran, 2005.
[18] D. T. Tuhfat al-mu'minin, The Present for the Faithfu, Research Center of Traditional Medicine: Nashre Shahr Press, Tehran, Iran, 2007, Shahr Press,, al-muminin (The Present for the Faithful)., Tehran, Research Center of Traditional Medicine: Nashre.

[19] A. Shirazi, Makhzan al-adviyah (The Storehouse of Medicaments), Tehran University of Medical Sciences: Institute for Islamic and Complementary Medicine, Tehran, Iran, 2009.

[20] G. R. Amin, Popular Medicinal Plants of Iran, Iranian Research Institute of Medicinal Plants, Tehran, Iran, 1991.

[21] A. Ghahreman and A. R. Okhovvat, Matching the old medicinal plant names with scientific terminology, University of Tehran Press, 2004.

[22] V. Mozaffarian, A dictionary of Iranian plant names: Latin, English, Persian, Farhang Mo'aser, 1996.

[23] A. Soltani, Dictionary of medicinal plants, Arjmand Press, Tehran, Iran, 2004.

[24] F. Rabizadeh and A. Okhovat, Okhovat A. Increasing certainty in use of medicinal plants in traditional medicine with identifying their scientific name. Islamic and Iranian traditional medicine, vol. 1, Islamic and Iranian traditional medicine, 2009.

[25] S. A. Emami, S. Fasihi, and I. Mehrgan, 2009, Reference Book of Medicinal Plants in Persian Medical history research institute.

[26] R. Rahimi, G. Amin, and M. R. S. Ardekani, "A review on citrullus colocynthis schrad.: From traditional iranian medicine to modern phytotherapy," The Journal of Alternative and Complementary Medicine, vol. 18, no. 6, pp. 551-554, 2012.

[27] M. Mosaffa Jahromi, H. Ghaemi, M. Ajdary Tafti, A. Arabzadeh, and S. Afsharypuor, "Vaginal and Rectal Dosage Forms in Iranian Traditional Pharmacy," Jundishapur Journal of Natural Pharmaceutical Products, vol. 10, no. 2, 2015.

[28] D. H. Kort and R. A. Lobo, "Preliminary evidence that cinnamon improves menstrual cyclicity in women with polycystic ovary syndrome: a randomized controlled trial," American Journal of Obstetrics \& Gynecology, vol. 211, no. 5, pp. 487.el487.e6, 2014.

[29] E. Mohebbi-Kian, S. Mohammad-Alizadeh-Charandabi, and R. Bekhradi, "Efficacy of fennel and combined oral contraceptive on depot medroxyprogesterone acetate-induced amenorrhea: A randomized placebo-controlled trial," Contraception, vol. 90, no. 4, pp. 440-446, 2014.

[30] R. Mokaberinejad, N. Zafarghandi, S. Bioos et al., "Mentha longifolia syrup in secondary amenorrhea: A double-blind, placebo-controlled, randomized trials," DARU Journal of Pharmaceutical Sciences, vol. 20, no. 1, article no. 97, 2012.

[31] R. Mokaberinejad, E. Akhtari, M. Tansaz et al., "Effect of Mentha longifolia on FSH Serum Level in Premature Ovarian Failure," Open Journal of Obstetrics and Gynecology, vol. 4, no. 7, pp. 356-360, 2014.

[32] T. Ushiroyama, A. Ikeda, M. Sakai et al., "Effects of unkei-to, an herbal medicine, on endocrine function and ovulation in women with high basal levels of luteinizing hormone secretion," Obstetrics, Gynaecology and Reproductive Medicine, vol. 46, no. 5, pp. 451-456, 2001.

[33] M. Yavari, S. Rouholamin, M. Tansaz, S. Bioos, and S. Esmaeili, "Sesame a treatment of menstrual bleeding cessation in iranian traditional medicine: Results from a pilot study," Shiraz E Medical Journal, vol. 15, no. 3, Article ID e21893, 2014.

[34] M. Yavari, S. Rouholamin, M. Tansaz, S. Bioos, and S. Esmaeili, "Sesame a Treatment of Menstrual Bleeding Cessation in Iranian Traditional Medicine: Results From a Pilot Study," Shiraz E Medical Journal, vol. 5, no. 3, pp. 114-121, 2016. 
[35] M. H. Bashtian, S. A. Emami, N. Mousavifar, H. A. Esmaily, M. Mahmoudi, and A. H. M. Poor, "Evaluation of fenugreek (Trigonella foenum-graceum L.), effects seeds extract on insulin resistance in women with polycystic ovarian syndrome," Iranian Journal of Pharmaceutical Research, vol. 12, no. 2, pp. 475-481, 2013.

[36] A. Swaroop, A. S. Jaipuriar, S. K. Gupta et al., "Efficacy of a novel fenugreek seed extract (Trigonella foenum-graecum, furocyst ${ }^{\mathrm{TM}}$ ) in polycystic ovary syndrome (PCOS)," International Journal of Medical Sciences, vol. 12, no. 10, pp. 825-831, 2015.

[37] F. Najafipour, AO. Rahimi, M. Mobaseri, N. Agamohamadzadeh, A. Nikoo, and A. Aliasgharzadeh, "Therapeutic effects of stinging nettle (Urtica dioica) in women with Hyperandrogenism," Int J Current Res Acad Rev, vol. 2, no. 7, pp. 153-160, 2014.

[38] J. Bergmann, B. Luft, S. Boehmann, B. Runnebaum, and I. Gerhard, "Phyto-Hypophyson ${ }^{\circledR} \mathrm{L}$ for female infertility. Randomized, placebo-controlled, clinical double-blind study," Forschende Komplementärmedizin und klassische Naturheilkunde, vol. 7, no. 4, pp. 190-199, 2000.

[39] M. Shahnazi, A. F. Khalili, K. Hamdi, and P. Ghahremaninasab, "The effects of combined low-dose oral contraceptives and Vitex agnus on the improvement of clinical and paraclinical parameters of polycystic ovarian syndrome: A triple-blind, randomized, controlled clinical trial," Iranian Red Crescent Medical Journal, vol. 18, no. 12, Article ID e37510, 2016.

[40] The Plant List, 2013, http://www.theplantlist.org/.

[41] M. Nabiuni, S. Doostikhah, S. R. Panahandeh, and L. Karimzadeh, Hydro-alcoholic extract of Ziziphora tenuior $L$. on polycystic ovary syndrome in Wistar rats, vol. 73, Tehran University Medical Journal TUMS Publications, 2015.

[42] M. Jafarisani, M. Masoomikarimi, SS. Kazemi, S. Mirzaeidelaviz, Z. Naderi, and R. Ahmadi, "Effect of Thymus Vulgaris Ethanol Extract, on Serum Total Antioxidant in Experimental Induced Poly Cystic Ovarian Syndrome (PCOs) Rats," International Journal of Health Studies, pp. 30-34, 2016.

[43] I. Haj-Husein, S. Tukan, and F. Alkazaleh, "The effect of marjoram (Origanum majorana) tea on the hormonal profile of women with polycystic ovary syndrome: A randomised controlled pilot study," Journal of Human Nutrition and Dietetics, vol. 29, no. 1, pp. 105-111, 2016.

[44] N. Anwar, S. Hamid, and SA. Butt, "Eeffect of Nigella sativa on number of cystic follicles in letrozole induced polycystic ovaries in mice," Pakistan Armed Forces Medical Journal, vol. 66, no. 3, pp. 310-330, 2016.

[45] M. Arif, S. C. Thakur, and K. Datta, "Implication of thymoquinone as a remedy for polycystic ovary in rat," Pharmaceutical Biology, vol. 54, no. 4, pp. 674-685, 2016.

[46] F. Z. Zangeneh, B. Minaee, A. Amirzargar, A. Ahangarpour, and K. Mousavizadeh, "Mousavizadeh K. Effects of chamomile extract on biochemical and clinical parameters in a rat model of polycystic ovary syndrome," Journal of Reproduction \&amp; Infertility, vol. 11, no. 3, p. 169, 2010.

[47] R. Mahood, "Effects of Pimpinella anisum oil Extract on Some Biochemical Parameters in Mice experimentally induced for human Polycystic Ovary Syndrome," J Biotec Res Cent, pp. 6773, 2012.

[48] A. Ghasemzadeh, L. Farzadi, A. Khaki, and S. K. Ahmadi, "Effect of Allium cepa seeds ethanolic extract on experimental polycystic ovary syndrome (PCOS) apoptosis induced by estradiol-valerate," Life Science Journal, vol. 10, no. 4, pp. 170$175,2013$.

[49] M. Tahvilzadeh, M. Hajimahmoodi, T. Toliyat, M. Karimi, and R. Rahimi, "An evidence-based approach to medicinal plants for the treatment of sperm abnormalities in traditional Persian medicine," Andrologia, vol. 48, no. 8, pp. 860-879, 2016.

[50] M. Amoura, Z. H. Lotfy, E. Neveen, and A. Khloud, "Potential effects of Mentha piperita (peppermint) on Letrozole-induced polycystic ovarian syndrome in female albino rat," International Journal, vol. 3, no. 10, pp. 211-226, 2015.

[51] S. Dars, K. Sayed, and Z. Yousufzai, "Relationship of menstrual irregularities to BMI and nutritional status in adolescent girls," Pakistan Journal of Medical Sciences, vol. 30, no. 1, pp. 140-144, 2014.

[52] M. Yavari, F. Khodabandeh, M. Tansaz, and S. Rouholamin, "A neuropsychiatric complication of oligomenorrhea according to Iranian traditional medicine," Iranian Journal of Reproductive Medicine, vol. 12, no. 7, pp. 453-458, 2014.

[53] B. Fauser, B. Tarlatzis, R. Rebar, R. Legro, A. Balen, R. Lobo et al., "Amsterdam ESHRE/ASRM-Sponsored 3rd PCOS Consensus Workshop Group (2012) Consensus on women's health aspects of polycystic ovary syndrome (PCOS)," Hum Reprod, vol. 27, no. 1, pp. 14-24, 2012.

[54] L. Speroff and M. A. Fritz, Clinical Gynecologic Endocrinology and Infertility, lippincott Williams \& wilkins, 2005.

[55] C. E. Dennehy, "The use of herbs and dietary supplements in gynecology: an evidence-based review," Journal of Midwifery ¿amp; Women's Health, vol. 51, no. 6, pp. 402-409, 2006.

[56] S. A. Yassin, "Herbal remedy used by rural adolescent girls with menstrual disorders," J Am Sci, vol. 8, no. 1, pp. 467-473, 2012.

[57] A. Zargaran, A. Borhani-Haghighi, P. Faridi, S. Daneshamouz, and A. Mohagheghzadeh, "A review on the management of migraine in the Avicenna's Canon of Medicine," Neurological Sciences, vol. 37, no. 3, pp. 471-478, 2016.

[58] A. Scalbert, C. Andres-Lacueva, M. Arita et al., "Databases on food phytochemicals and their health-promoting effects," Journal of Agricultural and Food Chemistry, vol. 59, no. 9, pp. 4331-4348, 2011.

[59] S. Zare, M. Nabiuni, A. Tayanloo, S. Hoseini, and L. Karimzadeh-Bardei, "The effects of Urtica dioica extract on lipid profile, insulin resistance index and liver histology in polycystic ovary syndrome-induced Wistar rats," Advanced Herbal Medicine, vol. 1, no. 2, pp. 23-33, 2015.

[60] P. Mohammad, G. Liela, F. Mohsen, and K. J. Hossein, "The effect of hydro alcoholic cinnamon extract on changes of gonadotropins ( $\mathrm{LH}$ and $\mathrm{FSH}$ ) in mice treated with Cocodamol," Biomedical and Pharmacology Journal, vol. 7, no. 1, pp. 369-373, 2014.

[61] P. Karampoor, M. Azarnia, G. Mirabolghasemi, and F. Alizadeh, The Effect of hYdroalcoholic Extract of Fennel (Foeniculum Vulgare) Seed on Serum Levels of Sexual Hormones in Female Wistar rats with Polycystic Ovarian Syndrome (PCOS), 2014.

[62] G. Jelodar and K. Askari, "Effect of Vitex agnus-castus fruits hydroalcoholic extract on sex hormones in rat with induced polycystic ovary syndrome (PCOS)," Physiology and Pharmacology, vol. 16, no. 1, pp. 62-69, 2012.

[63] A. Milewicz, E. Gejdel, H. Sworen et al., "Vitex agnus castus extract in the treatment of luteal phase defects due to latent hyperprolactinaemia. Results of a randomized placebocontrolled double blind study," Arzneimittel-Forschung/Drug Research, vol. 43, no. 7, pp. 752-756, 1993. 
[64] S. Sadr Fozalaee, F. Farokhi, and F. Khaneshi, "The Effect of Metformin and Aqueous Extract Foeniculumvulgare (Fennel) on EndometrialHistomorphometry and the Level of Steroid Hormones in Rats with Polycystic Ovary Syndrome," Qom University of Medical Sciences Journal, vol. 8, no. 5, pp. 12-19, 2015.

[65] G. A. Jelodar and E. Karami, "Effect of hydroalcoholic extract of vitex agnus-castus fruit on ovarian histology in rat with induced Polycystic Ovary Syndrome (PCOS)," Journal of BABOL University of Medical Sciences, vol. 12, no. 3, pp. 96-102, 2013.

[66] E. Pages, "Consensus on women's health aspects of polycystic ovary syndrome (PCOS)," Hum Reprod, vol. 27, no. 1, pp. 14-24, 2012. 


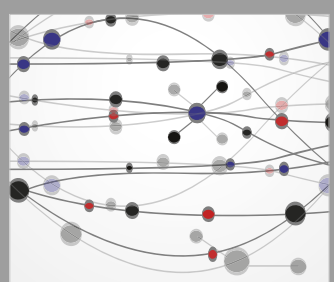

The Scientific World Journal
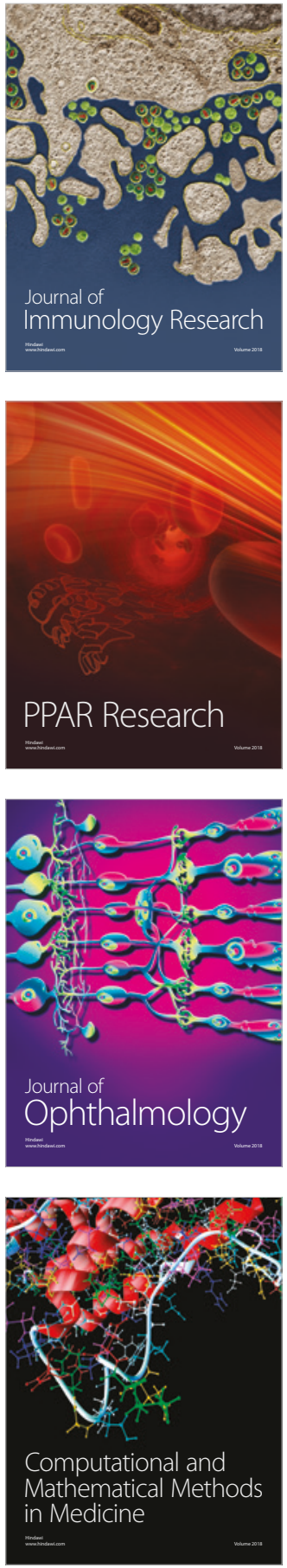

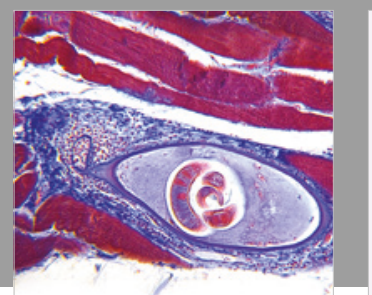

Gastroenterology Research and Practice

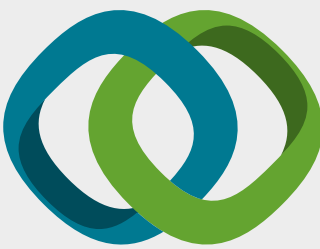

\section{Hindawi}

Submit your manuscripts at

www.hindawi.com
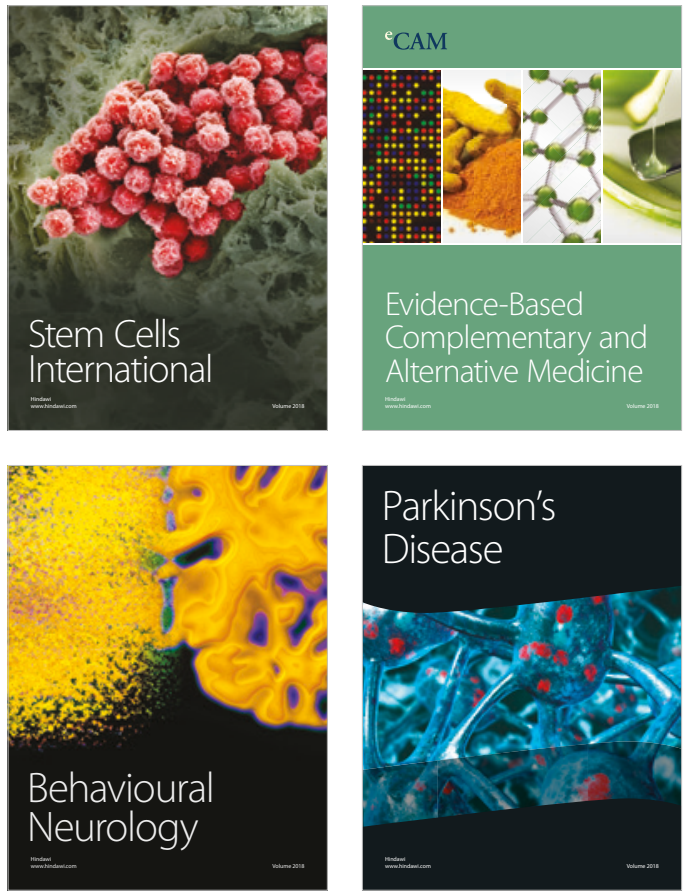

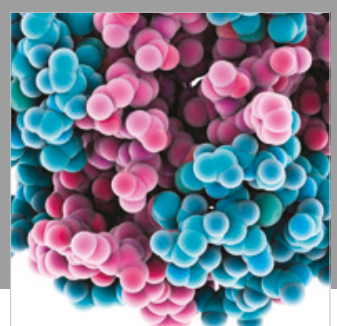

ournal of

Diabetes Research

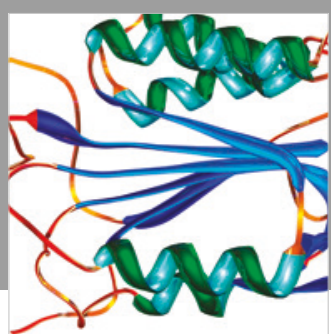

Disease Markers
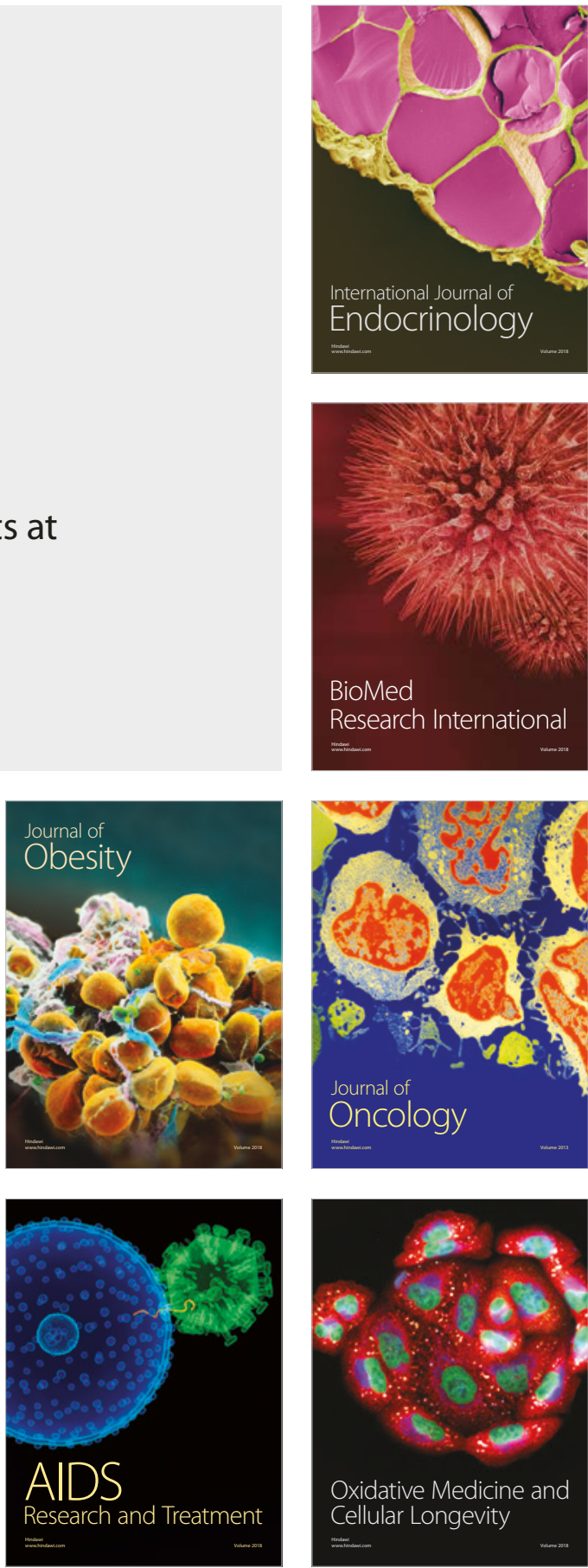